\title{
RAIL CAR IMPACT TESTS WITH STEEL COIL: COLLISION DYNAMICS
}

\author{
Karina Jacobsen \\ David Tyrell \\ Volpe National Transportation Systems Center \\ US Department of Transportation \\ Cambridge, MA 02142 USA \\ Benjamin Perlman \\ Tufts University \\ Medford, Massachusetts
}

\section{ABSTRACT}

Two full-scale oblique grade-crossing impact tests were conducted in June 2002 to compare the crashworthiness performance of alternative corner post designs on rail passenger cab cars. On June 4, 2002 a cab car fitted with an end structure built to pre-1999 requirements impacted a steel coil at approximately $14 \mathrm{mph}$. Following, on June 7, 2002 a cab car fitted with an end structure built to current requirements underwent the same test. Each car was equipped with strain gauges, string potentiometers and accelerometers to measure the deformation of specific structural elements, and the longitudinal, lateral and vertical displacements of the car body. The gross motions of the cars and steel coil, the force/crush behavior of the end structures, and the deformation of major elements in the end structures were measured during the tests.

During the first test, the car fitted with the 1990's design end structure acquired more than 20 inches of longitudinal deformation causing failure at the corner post and resulting in the loss of operator survival space. During the second test, the corner post on the car fitted with the State-of-the-Art design deformed longitudinally by about 8 inches, causing no failure and consequently preserving the survivable operator volume. In both cases, the steel coil was thrown to the side of the train after impacting the end structure.

Prior to the tests, the crush behaviors of the cars and their dynamic responses were simulated with car crush and collision dynamics models. The car crush model was used to determine the force/crush characteristics of the corner posts, as well as their modes of deformation. The collision dynamics model was used to predict the extent of crush of the corner posts as functions of impact velocity, as well as the three-dimensional accelerations, velocities, and displacements of the cars and coil. Both models were used in determining the instrumentation and its locations. This paper describes the collision dynamics model and compares predictions for the gross motions of the cars and coils made with this model with measurements from the tests. A companion paper describes the car crush model and compares predictions made of car crush with measurements from the test.

The collision dynamics was analyzed using a lumped-parameter model, with non-linear stiffness characteristics. The suspension of the car is included in the model in sufficient detail to predict derailment. The model takes the force/crush characteristic developed in the car crush analysis as input, and includes the lateral force that develops as the corner post is loaded longitudinally.

The results from the full-scale grade-crossing impact tests largely agree with and confirm the preliminary results of the threedimensional lumped parameter computer model of the collision dynamics. The predictions of the model for the three-dimensional accelerations, velocities, and displacements of the car and the coil are in very close agreement with the measurements made in the tests of both cars, up to the time of failure of the corner post. The cars remained on the track in both tests, as predicted with the model.

\section{INTRODUCTION}

The grade-crossing impact tests are a component of an ongoing study of passenger car crashworthiness sponsored by the Federal Railroad Administration's (FRA's) Equipment Safety Research Program. A series of full-scale impact tests have been underway for three years, testing critical conditions for single-car, two-car, and full train collision scenarios. These tests measure and compare the collision performance of conventional and modified equipment $[1,2$, 3].

Table 1. Full-Scale Impact Tests

\begin{tabular}{|l|l|l|}
\hline Test Conditions & $\begin{array}{l}\text { Conventional Design } \\
\text { Equipment }\end{array}$ & $\begin{array}{l}\text { Improved } \\
\text { Crashworthiness } \\
\text { Design Equipment }\end{array}$ \\
\hline $\begin{array}{l}\text { Single-car } \\
\text { impacting fixed } \\
\text { barrier }\end{array}$ & November 16, 1999 & Test 6 \\
\hline $\begin{array}{l}\text { Two-car impacting } \\
\text { fixed barrier }\end{array}$ & April 4, 2000 & Test 7 \\
\hline $\begin{array}{l}\text { Cab car-led train } \\
\text { impacting } \\
\text { locomotive-led } \\
\text { train }\end{array}$ & January 31,2002 & Test 8 \\
\hline $\begin{array}{l}\text { Single-car } \\
\text { impacting steel coil }\end{array}$ & June 4, 2002 & June 7, 2002 \\
\hline
\end{tabular}


The overall objective of the Occupant Protection Research being conducted as part of the FRA's Equipment Safety Research Program is to develop strategies for preserving the occupant volume and minimizing the forces and decelerations imparted to occupants during collisions and derailments. To accomplish this, collision dynamics models are used to create the specific collision scenario and document both the loss of occupant volume and the effects of the collision on the occupant environment. This goal was broken down into specific objectives that led to the described test scenarios.

The primary objective of the grade-crossing impact test is to compare the crashworthiness performance of the Pre-1999 and Post1999 corner post designs for cab cars. These tests serve to compare the crashworthiness of the two corner post designs when presented with the unique circumstances caused by a grade-crossing collision. The first test will determine the current standard of safety and the second test will demonstrate the improved level of safety required by the FRA and APTA research program. The final results verify the effectiveness of the structural modifications.

A secondary objective of the grade-crossing impact tests is to verify the computer models developed to simulate the structural and dynamic conditions. Prior to the full-scale tests, both finite element and collision dynamic models were created to assist in setting up and predicting the result of the collision. The results of the full-scale test can then be used to validate and revise the models. These models are valuable in predicting the outcome of similar collision scenarios.

The grade-crossing collision scenario consisted of a single cab car on a tangent track obliquely impacting a steel coil supported by a frangible table at $14 \mathrm{mph}$. Specific test objectives identified to obtain the necessary results and measurements in the collisions are as follows:

1.) Measure gross motions of the cab car

2.) Measure gross motions of the steel coil

3.) Measure the force/crush behavior of the cab car end structure

4.) Observe specific failure modes of the corner post in relation to the other structural components

5.) Observe the impacting interfaces interaction

6.) Observe the preservation of occupant volume

This paper compares the results of the full-scale grade-crossing collision to the collision dynamics model and assesses the overall occupancy protection. A companion paper discusses the analysis of the structural deformation of specific end structure members in relation to the finite element model developed for the test [4].

\section{BACKGROUND}

While grade-crossing collisions are typically not as destructive as train-to-train collisions, due to the motion and size of impacting bodies, they are significantly more frequent. A particularly destructive incident occurred in Portage, Indiana on June 18, 1998 [5]. A passenger train struck a semi-trailer pulling two flatbeds loaded with steel coils weighing 20 tons each. As the vehicles collided, the cables restraining the coils severed and an impacting coil broke through the end structure and bulkhead of the cab car and proceeded to crush through the passenger compartment. This collision resulted in five minor injuries and three fatalities.

Full-scale impact tests are necessary to develop analytical validation for our understanding of collisions. Controlled tests are particularly beneficial for gathering results for the following:

-large crush distances

-impacting surface interactions

-secondary impact environment
These results are used to create/validate models of the respective collision scenario, determine critical cases, better understand the results of specific scenarios, and ultimately, create crashworthiness regulations to improve occupant safety.

The motivation for the grade-crossing impact test stems from the desire to evaluate the improved performance of the corner posts as required by the updated FRA and APTA standards. The end structure of the cab car that impacts the steel coil is the area of primary structural concern. A passenger car end structure is composed of four vertical posts designed to a maximum strength in collisions. The structural analysis in the full-scale test focuses upon the corner post because of its critical position upon impact with an object at a gradecrossing.

Prior to 1995 load-bearing standards for specific structural members of passenger car end structures were dictated by unregulated industrial use standards. In 1995 the American Public Transportation Association (APTA) organized the Passenger Rail Equipment Safety Standards (PRESS) Committee to develop updated safety standards [6]. The FRA has regulations with minimum strength requirements for corner posts [7]. The APTA standards require that specific end structure elements support a static load without permanent deformation or failure. This standard requires that corner posts at the lead end of cab cars can withstand both a 45 kip force applied longitudinally or vertically at any height, a 100 kip longitudinal or vertical force applied 18 inches above the top of the underframe, and a 300 kip longitudinal or vertical force applied at the base. The APTA load requirements for cab car corner posts are illustrated in Figure 1.

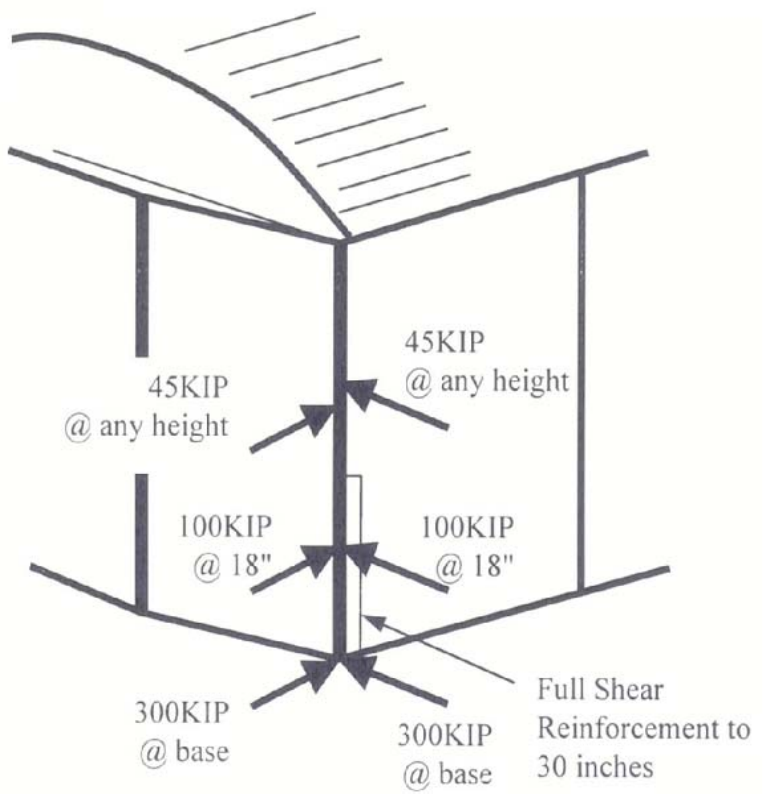

Figure 1. Schematic of APTA Corner Post Standards

\section{GRADE-CROSSING TEST DESCRIPTION}

Two similar tests took place involving a cab car traveling on tangent tracks colliding obliquely into a $41,300 \mathrm{lbm}$ steel coil raised about four feet above the top of the rail on a frangible support - the base of the coil located two inches above the substructure. This testing setup was chosen both to test current standards and to approximate the 1998 Portage, Indiana collision because a vulnerability of the end structure was made obvious in that incident. As demonstrated in that 
scenario, when a heavy rigid object is elevated above the substructure of the passenger car, the vertical beams in the end structure are required to withstand the full intensity of the initial impact. According to the regulatory standards, the corner posts have a lower load requirement than the collision posts. In the event of a grade-crossing collision with a freight truck, heavy objects may potentially challenge the strength of individual posts. These vertical beams are the primary guard against intrusion into the passenger compartment.

Both test cab cars were Pioneer cab cars designed by Budd Company [8]. Two cab cars were fitted with a new end structure: one a 1990's end frame, designed to pre-1999 industry standards, and the second with a State-of-the-Art (SOA) end frame, designed to meet current FRA regulations and APTA standards (updated in 1999).

In the first test the cab car, fitted with an end frame built to the 1990's design, impacted the coil at a speed of $14.4 \mathrm{mph}$. Then, in the second test a cab car, fitted with an end frame built to the SOA design, impacted a coil at a speed of $14.0 \mathrm{mph}$. These speeds were chosen to induce significant deformation. Consequently, the energy absorbed by the two designs can be compared from the measurements of their deformation.

The 1990's end frame consists of four vertical beams (two collision posts and two corner posts), two primary horizontal beams (the end beam and anti-telescoping plate) and includes a step well. The SOA end frame also consists of four vertical beams, two primary horizontal beams, but includes a continuous side sill and front facing sheets connecting the lateral member to the end beam. See Figure 2 for the design comparisons. The companion paper includes more detailed descriptions of the end structures [4].

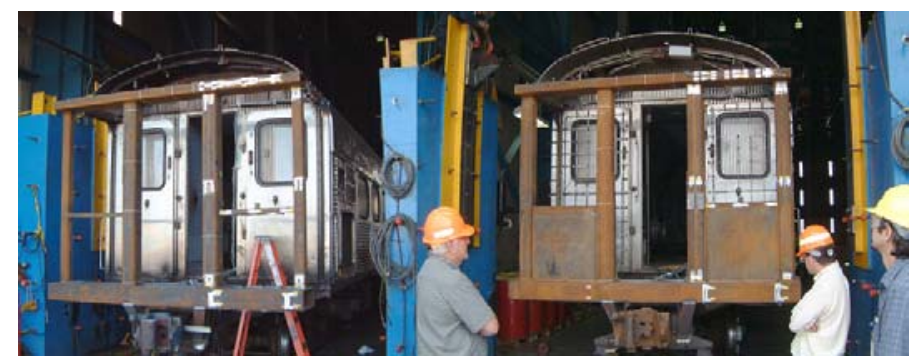

Figure 2. Photographs of 1990's and SOA End Frames

A collection of 125 data channels was strategically placed throughout the cab car to measure material strain, accelerations in three dimensions, and vertical displacements of the truck suspension. The end structure of the cab car was instrumented with 76 strain gauges to capture the deformation and load paths of the following structural elements: end beam/buff wing, collision posts, corner posts, cant rail, draft/center sill, side sill and lateral members (both below the window and the anti-telescoping plate). Displacement transducers were also set up on each truck. The steel coil was instrumented with a total of 9 data channels, measuring motions in three dimensions.

The test was documented using a set of eight high-speed cameras and four video cameras. These were positioned to capture the modes of deformation at the impacting area of the two bodies, while still able to film the full trajectory of the colliding bodies. Following the test, photometric analysis of the high-speed film is used to follow target points, labeled on the cab car, providing a secondary set of data. This data provides reliable information about both displacements and correspondingly, velocities and accelerations of these specified target points. The test instrumentation is described in more detail in Appendix A.

\section{MODELING APPROACH}

The chart shown in Figure 3 describes the approach used in developing and understanding a full-scale test. The iterative nature of the process allows for continued testing and development, contributing to an extensive understanding of the vehicle's crashworthiness. A finite element model is initially used to estimate the structural modes of deformation of the impacting bodies; subsequently, the forces absorbed by the impacting body can be extracted in relation to longitudinal deformation. These force-crush characteristics are used in a collision dynamics model, from which relative displacements, gross motions and secondary impact data can be produced. Interior occupant models require the data from the collision dynamics model. The three models are used to predict and create the appropriate conditions in the full-scale models, as well as accept updated data from the tests. Once authenticated by the full-scale test results, the collision dynamics model can then be used to predict results under similar collision conditions.

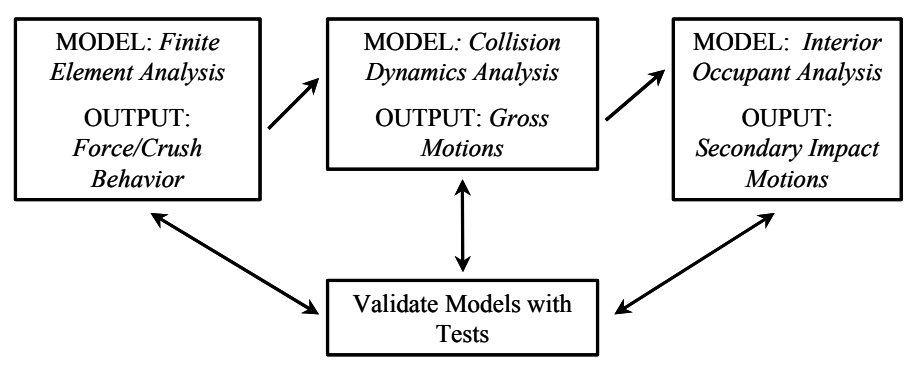

Figure 3. Modeling Process Flowchart

In preparation for the full-scale tests, finite element models were developed to predict the force-crush behavior of the grade-crossing collision. Models of the two end structure designs, 1990's and SOA, were carefully developed with the appropriate material properties and geometries so that the effect of the impacting object could be traced through the primary vertical beams and their connecting structures. Each end frame was welded onto the front of a Pioneer cab car, built by the Budd Company. A complementary paper [4] is written on the details of this model, the analysis of the structural deformation of the end structures, and their design strengths in relation to their respective standards. From these models, the modes of crush in each element were predicted, as well as the comprehensive force crush behavior for the 1990's and SOA end frames.

Collision dynamics models were created using ADAMS software [9] to evaluate the collision results. This three-dimensional model predicts the crush of the cab car and the three-dimensional motions of the coil and the cab car.

The collision dynamics (CD) model is a lumped-mass representation of the cab-car and the steel coil. As shown in Figure 4, the model consists of a series of masses connected by non-linear springs. The longitudinal springs use the force-crush characteristic obtained from a finite element (FE) model, which simulates the crush behavior of the end structure. Set with the appropriate initial conditions, the $\mathrm{CD}$ model provides the gross motions of the cab car and the coil and the amount of deformation at the impacting end of the cab car. The lateral deflection of the coil is modeled in a similar manner as the CD model developed for analyzing an oblique collision of locomotive with a container [10], which in turn evolved from the $\mathrm{CD}$ model developed for analyzing an oblique collision of a locomotive-led consist with a cab car-led consist [11]. 


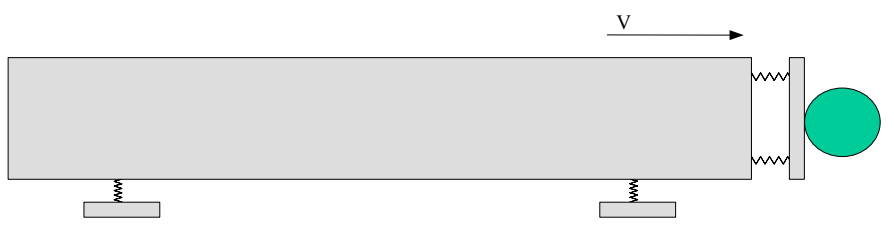

Figure 4. Schematic of Lumped-Mass Collision Dynamics Model

\section{TEST AND ANALYSIS RESULTS}

During the full-scale test, the force on the 1990's design end structure exceeded the corner post's predicted failure point and the corner post separated from its upper attachment. Upon impact, the corner post began to hinge near the contact point with the coil; subsequently tearing at the upper connection occurred. The intensity of the impact ultimately caused the upper connection of the corner post and anti-telescoping plate to fail. More than 30 inches of deformation occurred. The SOA design performed very closely to pre-test predictions made by the finite element and collision dynamics models. The SOA design crushed approximately 9 inches in the longitudinal direction. Post-collision photographs are shown in Figure 5.
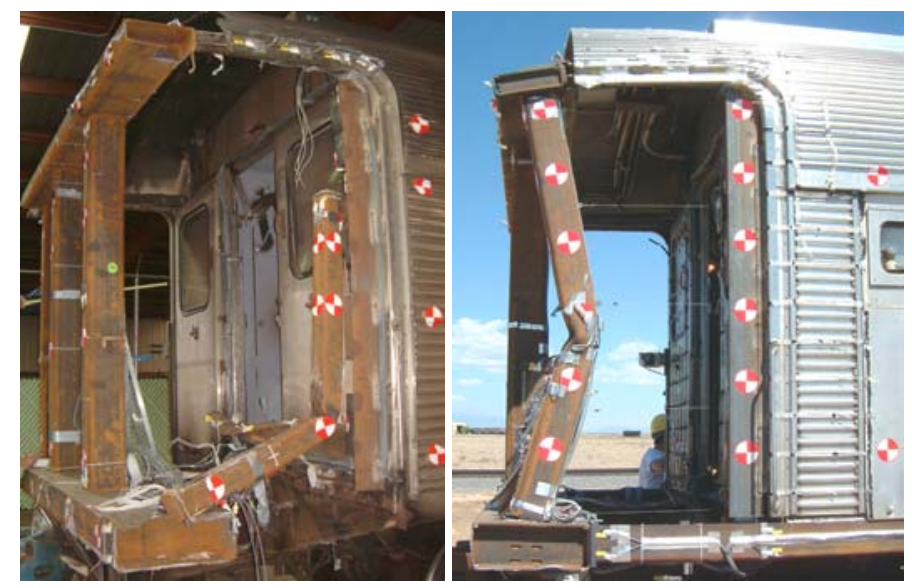

Figure 5. Post-Test Photographs, 1990's and SOA End Frames

\section{Force/Crush Behavior}

The combined results of the FE and CD models provide the predictions necessary to create a focused full-scale test. The FE model established the limits within which the collision must occur. The collision dynamics model used the force-crush curves from the FE model prior to the test, to estimate the corresponding collision speeds bounded by the desired deformation. The curves were entered into the collision dynamics model as the non-linear force-crush characteristics of the specific end structures. The collision dynamics model was used to estimate the extent of crush of the cab car as a function of the impact velocity.

Following the full-scale test, the force/crush characteristics input into the CD model can be updated with the test measurements. The pre-test prediction for the 1990's cab car force/crush characteristic proved accurate up to about 12 inches. After this point in the fullscale test, the corner post pulled out of its upper attachment at the antitelescoping plate. After the test, the input for the 1990's CD model was updated with force/crush from the processed test data. With this one change, the 1990's model results compare closely with the test results for the amount of cab car crush and for the gross motions of the cab car and coil. The SOA cab car test went nearly exactly as simulated, with approximately 9 inches of longitudinal deformation occurring in the corner post. Consequently, the input to the SOA CD model did not require post-test changes. Figures 6 and 7 show the pre-test and post-test force-crush curves.

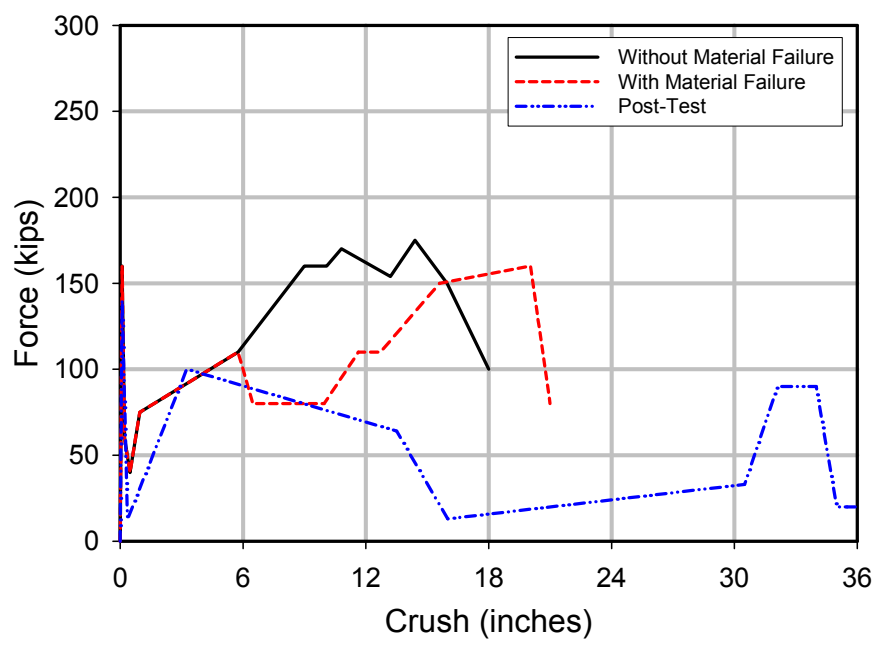

Figure 6. 1990's Force Crush Characteristics

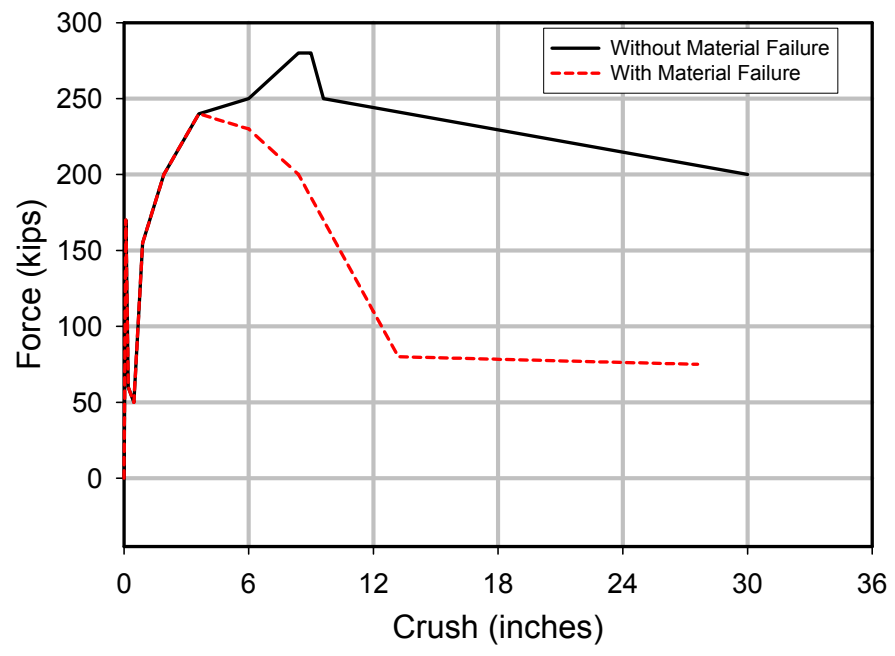

Figure 7. SOA Force Crush Characteristics

\section{Crush}

Figure 8 shows a plot of the cab car maximum crush as a function of the impact speed. These analyses results were used in developing the test requirements, to determine the desired impact speed of 15 mph. A single collision speed was chosen in order to cause significant deformation of the corner post during the tests, with the expectation that the operator's volume would be preserved in the test of the SOA design, i.e., that the intrusion into the occupant volume would be less than 12 inches. For the test of the 1990's design, it was expected that the deformation of the corner post would exceed 12 inches, and consequently intrude into the operator's survival volume. Prior to the tests, the 1990's design corner post was predicted to fail for an impact speed greater than $16 \mathrm{mph}$. During its test, the corner post of the 1990's design cab car end structure failed at the tested impact speed of 
$14.4 \mathrm{mph}$, a speed approximately $10 \%$ slower than predicted. The graph in Figure 8 shows that the increased standards for the corner posts prove more effective in crashworthiness protection.

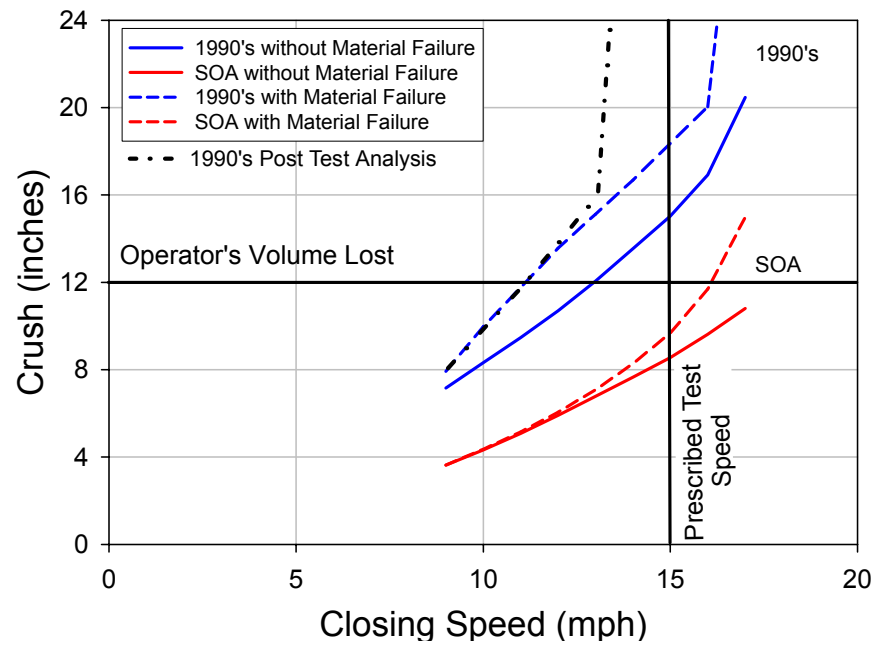

Figure 8. Comparison of Crush Estimation Vs. Initial Collision Speed

\section{Gross Motions}

During both tests, the cab cars impacted the heavy object, demolished the frangible table, and continued along the track at a decreasing velocity. In the 1990's cab car impact test the impact of the heavy object broke through the corner post. The steel coil became momentarily embedded in the end structure and then fell beside the cab car. During the SOA cab car collision, the impact of the steel coil caused about 9 inches of longitudinal deformation in the corner post, after which the coil fell from the cab car onto the track. During the impacts, when the coil and the car were in contact, the lateral and vertical displacements of the coil and the car were small - less than 1 inch. The yaw displacements of the coil, as it deflected from the cab car, were significant in both tests - approximately 19 degrees from the 1990 's cab car test and 4 degrees for the SOA cab car test. With the revised input force/crush characteristic, the predictions of the $\mathrm{CD}$ model with the 1990's design end structure are in close agreement with the test measurements, including the yaw of the coil. The predictions of the CD model of the test of the cab car with the SOA end frame are also in close agreement with the test measurements.

The deceleration records for the two impact tests are displayed in Figures 9 and 10, plotted with corresponding data from the collision dynamics model. While in contact, the coil and the car body acceleration histories are essentially mirrors of each other, scaled according to weight.

The cab car that had been modified with the 1990's end structure had previously been used in the single car test [1] and the cab car that had been modified with the SOA end frame had been the lead car in the two-car impact test [2]. Since the back ends of both cars were open during the grade-crossing tests, the body shells were relatively free to vibrate. As a result, the cab car data had to be filtered with a lower bandwidth filter. The cab car data was filtered with a CFC 15 filter, while the coil data was filtered with a CFC 60 filter [12]. The CFC 15 filtering resulted in less than $1 \%$ error in the displacement of the cab car as integrated from the accelerometer data, for both tests [13].

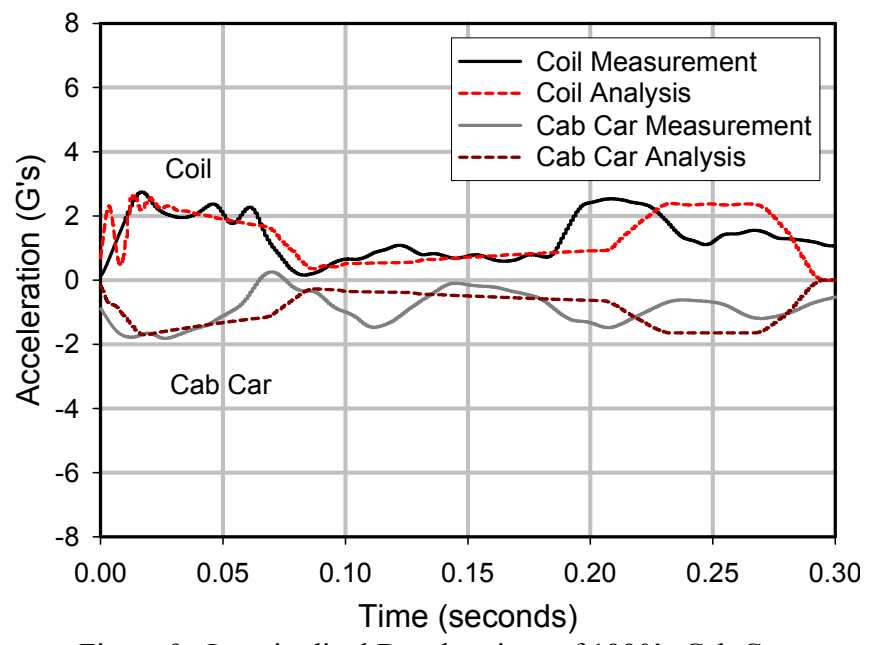

Figure 9. Longitudinal Decelerations of 1990's Cab Car

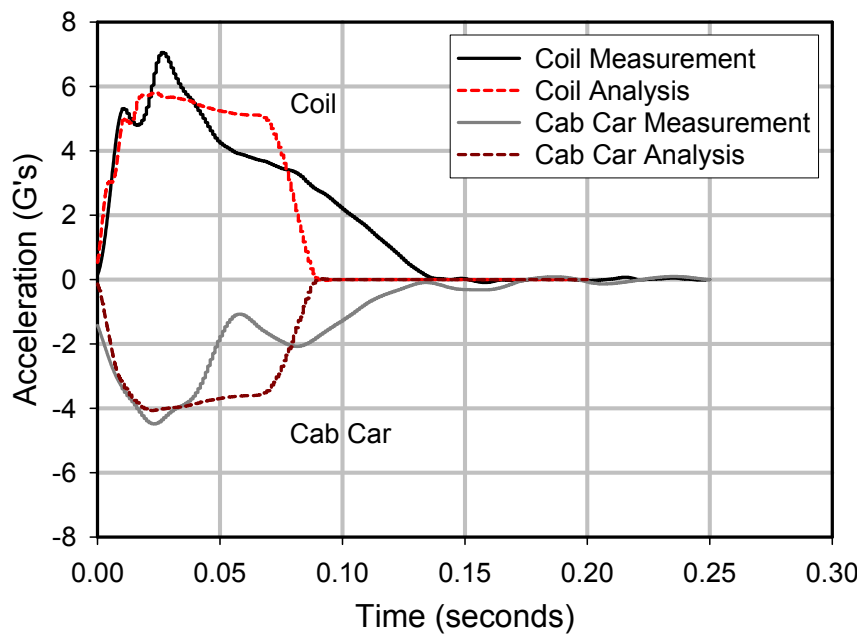

Figure 10. Longitudinal Decelerations of SOA Cab Car

The collision dynamics model reproduces the test longitudinal car body accelerations very closely. It captures the initial peak deceleration due to impact followed by a reasonable estimate of the car body motions. From the above figures, it is apparent that the data extracted from the coil instrumentation has significantly less noise than the car body instrumentation. Consequently, the coil acts effectively as a force-transducer for comparison and revision of test data with the model results.

The difference between the 1990's and SOA designs is evident in these results. The SOA design displays higher accelerations due to the increased strength of the end structure required by the revised 1999 APTA standards. The 1990's design receives lower accelerations over a longer time period, indicative of the prolonged deformation. The failure is seen in the drop-off of acceleration at around 0.1 seconds, as the corner post gives way and briefly looses contact with the coil.

The raw accelerometer data was integrated to produce the velocity-time histories. The comparison of the model results to the test data are shown in Figures 11 and 12. The collision dynamics models accurately predict the gradient of speed and final time at which the colliding bodies come to a constant velocity. 


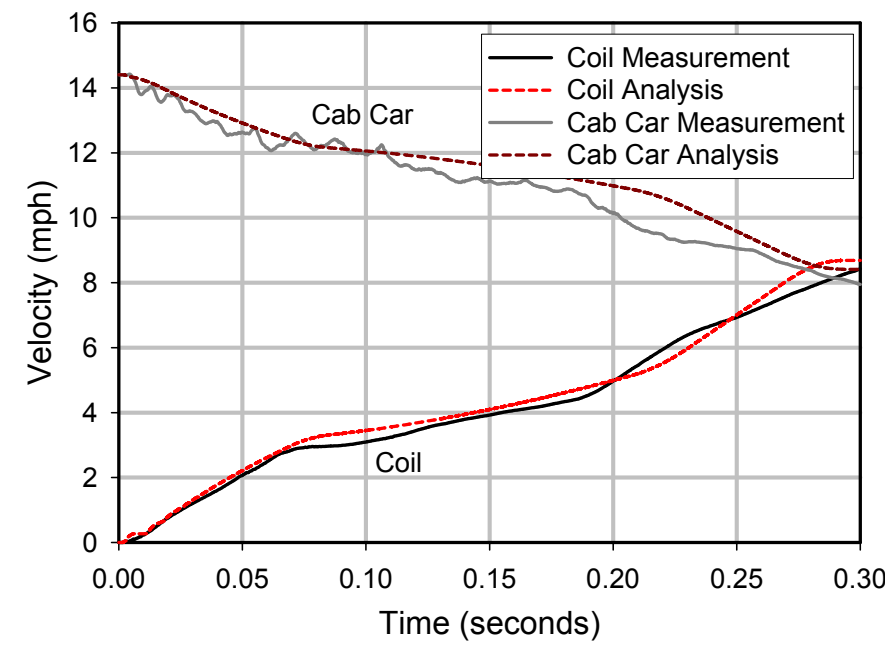

Figure 11. Velocity-Time History of 1990's Cab Car

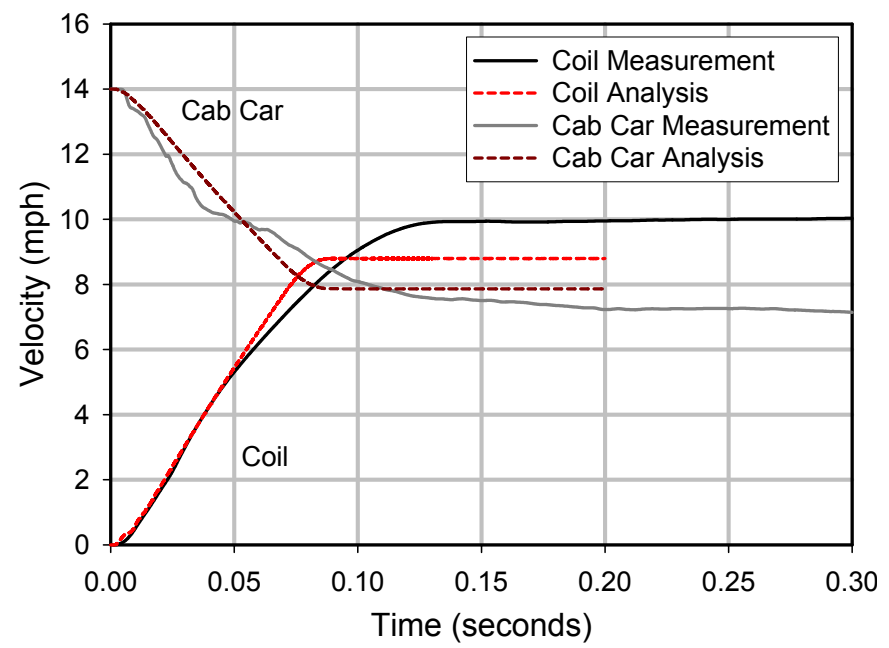

Figure 12. Velocity-Time History of SOA Cab Car

In both collisions the trains arrive at a post-impact velocity of about $8 \mathrm{mph}$. The SOA cab car impact takes approximately half the time of the 1990's cab car impact to reach this constant velocity due to the increased stiffness of the SOA design.

Accelerometers measuring lateral and vertical car body motions were analyzed and these motions were found to be negligible. The lateral and vertical displacements of the cab car and coil were all less than 1 inch while they were in contact, for both tests. Peak lateral car body accelerations ranged from 2-3 Gs in the first 0.03 seconds and are primarily attributed to the initial impact of the heavy object at the corner, causing a slight moment about the train's center of mass. While these lateral forces were identified to be of a characteristic pattern seen in larger scale collisions in which derailment occurred, the magnitude of the lateral forces was well below a state of concern [11]. After initial impact, lateral accelerations were less than $1 \mathrm{G}$.

The CD model also accurately predicts the yaw of the coil. Comparisons of the coil's rotational acceleration about the vertical axis are shown in Figures 13 and 14. The coil yaw acceleration is reflective of the pattern of the contact force. In the 1990's cab car test, the coil shows a peak rotational acceleration of about 22 radians per second squared. The collision dynamics model predicts a yaw acceleration of about 20 radians per second squared. The second significant peak, occurring at about 0.2 seconds shows when the coil breaks through the corner post and impacts the passenger compartment wall. This second peak in the yaw acceleration occurs because the contact point on the coil is different for the rear of the doorframe than it is for the corner post. The CD model currently does not account for this shift, although it could be modified. The SOA cab car comparison shows that the collision dynamics model follows the slope of the test data very precisely. Double integrating the test data produces a final rotational displacement of about 20 degrees. The still shots shown in Figure 15 depict general visual agreement with the position of the rotated coil.

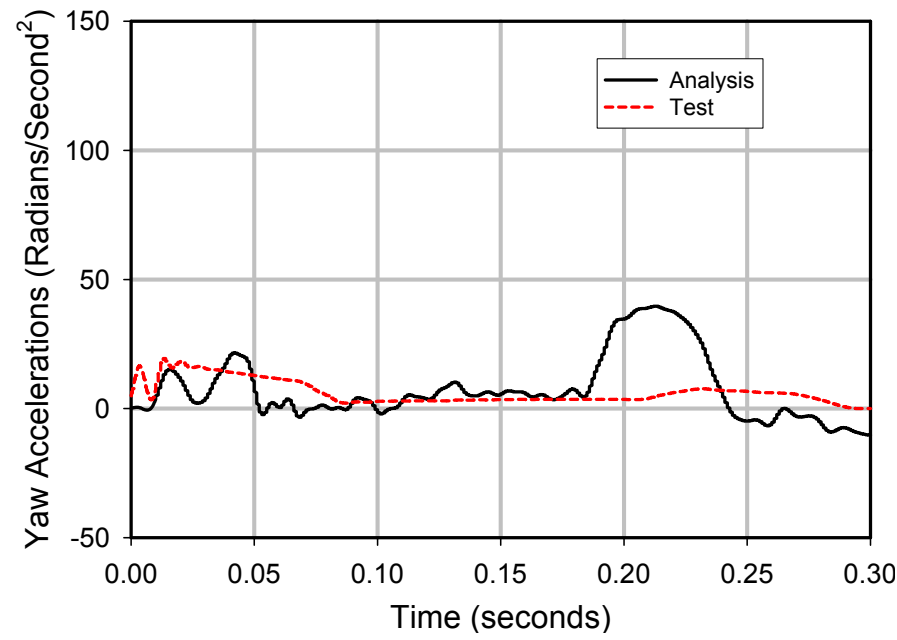

Figure 13. Comparison of Coil Yaw Acceleration, 1990's Cab Car Impact, Test Data and Analysis Results

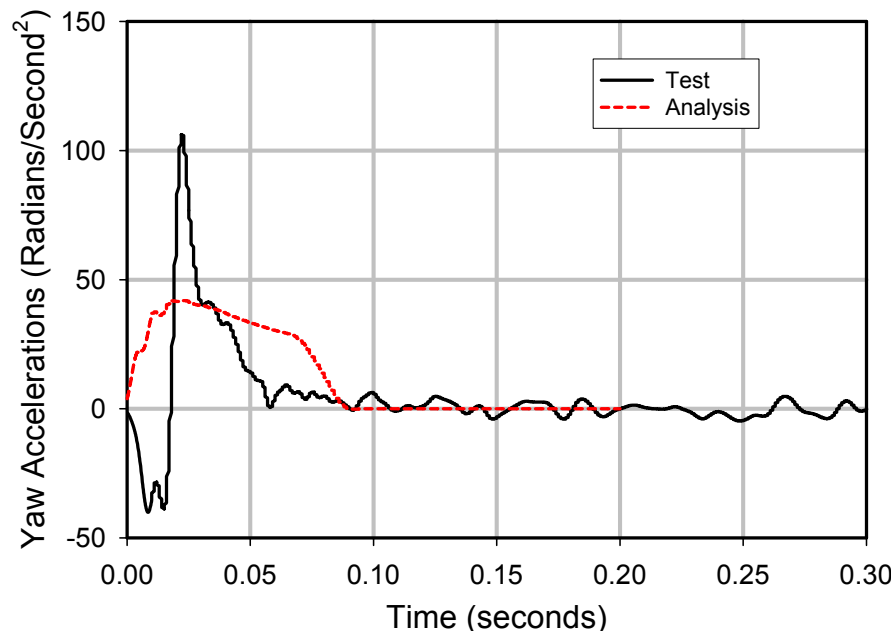

Figure 14. Comparison of Coil Yaw Acceleration, SOA Cab Car Impact, Test Data and Analysis Results

The CD models estimated the gross motions of the objects with relative accuracy. Figure 15 shows still shots from an overhead view of the collision dynamics simulation in comparison with the high speed camera of the 1990's full-scale collision. The pictures show the position at which the coil:

- $\quad$ initially impacts the train (indicated by the flash of lights on the side of the passenger car),

- breaks through the corner post,

- $\quad$ and impacts the cab wall. 

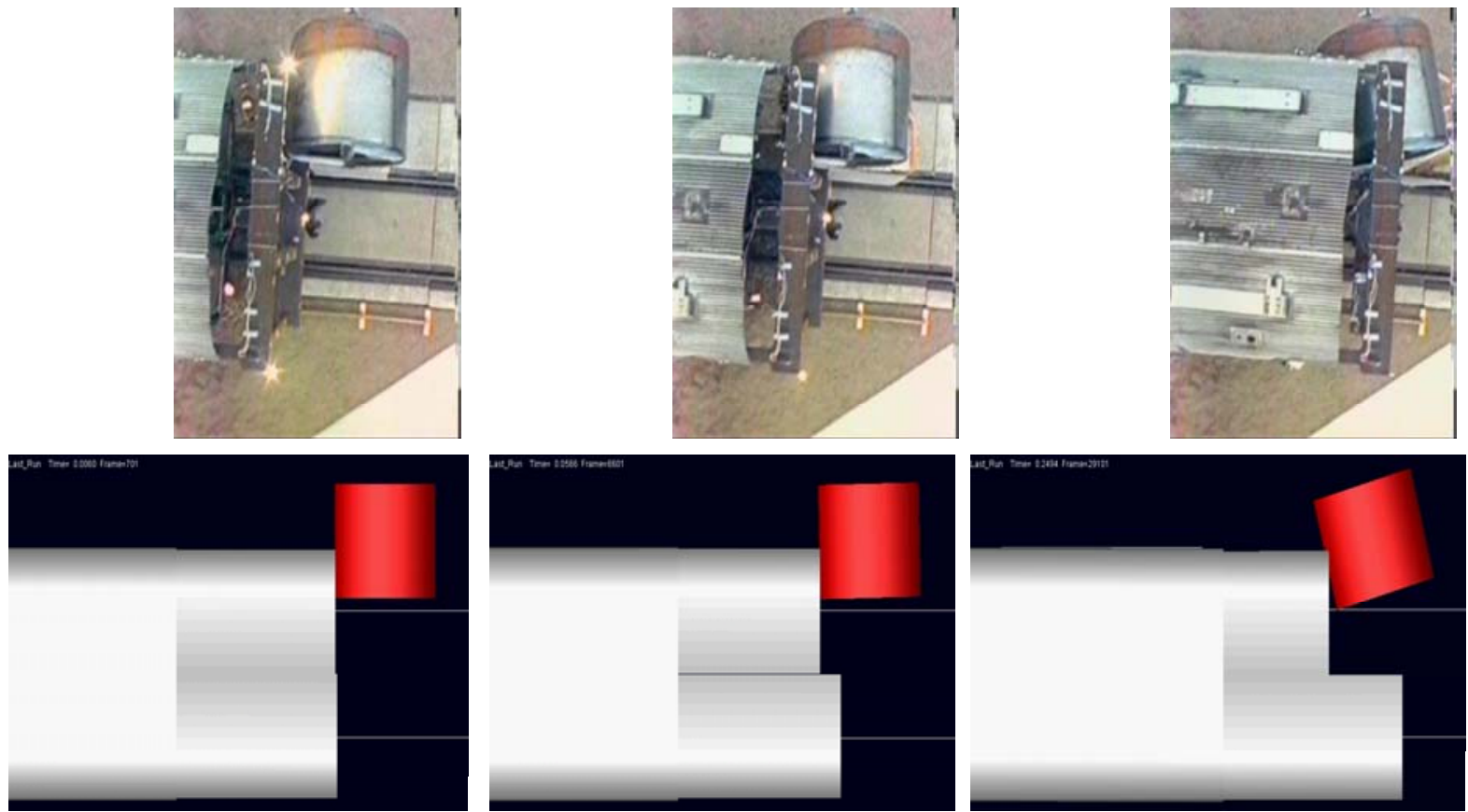

Figure 15. Still Photographs of Collision Dynamics Simulation and 1990's Full-Scale Test

\section{DISCUSSION AND CONCLUSIONS}

In the case of a specific grade crossing collision, a dense heavy object may impact the weakest vertical structural member of a cab car end structure. The integrity of this member prevents intrusion of the object into the passenger compartment. The grade crossing impact tests were designed to measure the weakest point in the end structure of a passenger car in an oblique collision and compare the performance of the conventional and improved end structure standards.

As proposed prior to the test, the collision dynamics model was developed to predict the gross motions of the colliding bodies, using the force-crush characteristic originally estimated by the finite element model and afterward updated with the test data. The model results presented demonstrate that the lumped-mass collision dynamics model predicts with reasonable accuracy the impact velocity/crush displacement behavior of the end structure and the gross motions of the train and coil in three dimensions.

All results demonstrate that the improved design standards for corner posts are effective. The 1990's design did not withstand the impact of the heavy object and the coil nearly intruded into the occupant compartment. In contrast, the SOA design withstood the impact of the heavy object under similar collision conditions.

Longitudinal and yaw accelerations of both the car body and heavy object were predicted closely in the 3-D collision dynamics models. The lateral forces created by the coil as it rotated about the corner post did not have any significant effect on the lateral motions of the passenger car. Further investigation would be necessary to determine the conditions for which a passenger car would derail in a similar grade-crossing collision.

Overall, the full-scale impact tests provide a good understanding of the fundamental dynamic behavior of rail equipment motions during collisions. With the appropriate force/crush curve for input, the 1990's CD model predicts 34 inches of crush of the cab car, and 20 degrees yaw rotation of the coil after the impact; 35 inches of crush and 19 degrees of rotation were observed during the test. The SOA CD model predicts 9 inches of crush and 6 degrees of rotation; 9 inches of crush and 4 degrees of rotation were observed in the test. With accurate input, the CD models can closely predict the dynamic response of the equipment involved in an impact.

\section{ACKNOWLEDGEMENTS}

Dr. Barrie Brickle, Senior Engineer, Transportation Technology Center, Inc. (now retired) was the test engineer who implemented the grade-crossing tests. Mr. Kent Johnson, President, Premier Engineering, and Dr. Ron Mayville, Manager, Applied Mechanics Unit, Tiax, LLC designed the SOA and 1990's end frames. Dr. Richard Stringfellow, Senior Engineer and Ms. Patricia Llana, Mechanical Engineer, Tiax, LLC developed the finite element models of the SOA and 1990's end frames. Dr. Steven Kirkpatrick, ARA, Inc developed the Pioneer Car finite element model, into which the end frame models were incorporated. Mr. Eloy Martinez and Mr. John Zolock, along with Mr. David Tyrell and Professor Benjamin Perlman, designed the grade-crossing tests.

The design of the tests was developed in coordination with the Construction/Structural Subcommittee of APTA's Passenger Rail Equipment Safety Standards Committee. The author's would like to thank Ken Barnish, Assistant Chief Mechanical Officer, Metro-North Railroad, Chair of the Subcommittee, and Tom Peacock, Manager, Technical Services, APTA for their efforts to coordinate the activities.

This work was performed as part of the Equipment Safety Research Program sponsored by the Office of Research and Development of the Federal Railroad Administration. The authors would like to thank Dr. Tom Tsai, Program Manager, and Claire Orth, Division Chief, Equipment and Operating Practices Research Division, Office of Research and Development, Federal Railroad Administration, for their support. The authors would also like to thank Gunars Spons, Federal Railroad Administration Resident Manager at the Transportation Technology Center, for managing the full-scale test effort. 


\section{REFERENCES}

[1] Tyrell, D., K. Severson, A.B. Perlman, "Single Passenger Rail Car Impact Test Volume I: Overview and Selected Results," U.S. Department of Transportation, DOT/FRA/ORD-00/02.1, March 2000.

[2] Tyrell, D., K. Severson, A.B. Perlman, "Passenger Rail Two-Car Impact Test Volume I: Overview and Selected Results," U.S. Department of Transportation, DOT/FRA/ORD-01/22.I, January 2002.

[3] Tyrell, D., Severson, K., Perlman, A.B., Rancatore, R., "Train-toTrain Impact Test: Analysis of Structural Measurements," American Society of Mechanical Engineers, Paper No. IMECE2002-33247, November 2002.

[4] Martinez, E., Tyrell, D., Zolock, J. "Grade-Crossing Impact Tests: Car Crush," to be presented at the 2003 ASME/IEEE Joint Rail Conference April 22-24, 2003; Chicago, Illinois, 2003.

[5] National Transportation Safety Board, "Collision of Northern Indiana Commuter Transportation District Train 102 with a TractorTrailer Portage, Indiana June 18,1998”, 07/26/1999, RAR-99-03.

[6] American Public Transportation Association, Member Services Department, Manual of Standards and Recommended Practices for Passenger Rail Equipment, Issue of July 1, 1999.

[7] U.S. Department of Transportation, Federal Railroad Administration, "49 CFR Part 216 et al., Passenger Equipment Safety Standards; Final Rule,” Federal Register, May 12, 1999.

[8] White, J.H., Jr., "The American Railroad Passenger Car," The Johns Hopkins University Press, 1978.

[9] ADAMS, Version 12.0.0, Mechanical Dynamics, Inc. Ann Arbor, Michigan.

[10] Tyrell, D., Severson, K., Marquis, B., Perlman, A.B., "Simulation of an Oblique Collision of a Locomotive and an Intermodal Container," Crashworthiness, Occupant Protection and Biomechanics in Transportation Systems, American Society of Mechanical Engineers, AMD Vol. 237/BED Vol. 45, 1999.

[11] Tyrell, D.C., Severson, K.J., Mayville, R.A., Stringfellow, R.G., Berry, S., Perlman, A.B., "Evaluation of Cab Car Crashworthiness Design Modifications," Proceedings of the 1997 IEEE/ ASME Joint Railroad Conference, Institute of Electrical and Electronics Engineers, Catalog Number 97CH36047, 1997.

[12] "Surface Vehicle Recommended Practices - Instrumentation for Impact Test,"SAE J211-1, the Society of Automotive Engineers, March 1995.

[13] Severson, K., Tyrell, D., Perlman, A.B., "Rail Passenger Equipment Collision Tests: Analysis of Structural Measurements," Rail Transportation, American Society of Mechanical Engineers, RTD-Vol. 19, 2000.

[14] Lee, H., Plank, G., Weinstock, H., Coltman, M. Methodology for the Calibration of the Data Acquisition with a Six-Degree-of-Freedom Acceleration Measurement Device, DOT-TSC-NHTSA-88-03, U.S. Department of Transportation, Transportation Systems Center, 1989.

\section{APPENDIX A - TEST REQUIREMENTS AND INSTRUMENTATION}

The primary objectives of the grade-crossing impact test instrumentation are to record the gross motions of the colliding bodies with sufficient accuracy to analyze and compare the data with model predictions. This is accomplished by instrumenting the passenger car and coil with strain gauges, accelerometers and string potentiometers, to record respectively, material strains, structural accelerations, and suspension displacements.

SAE J211-1, Instrumentation for Impact Tests provides general guidelines for all data acquisition [12]. For the 1990's test, 120 data channels was required for the instrumentation. There were 52 accelerometers, 9 string potentiometers and 80 strain gauges. For the SOA design, 132 channels were required for the instrumentation. There were 52 total accelerometers, 9 string potentiometers and 92 strain gauges. Data was recorded at a sampling rate of approximately $8000 \mathrm{~Hz}$. There was 1 second of pre-trigger data collection and 7 seconds of post-trigger data collection. A closure switch, located on the front of the impacting car marked all the data with a reference point indicating the point of impact in each record.

Accelerometers are used to measure the car body gross motions in three-dimensions as well as the pitch, yaw and roll. Accelerometer locations are shown in Figure A1. Accelerometers placed throughout the car body, also capture the bending and twisting about the car body axis. All longitudinal accelerometers had a range of 200-1000 Gs, vertical accelerometers had a range of $100-400 \mathrm{Gs}$, and most lateral accelerometers were 200 Gs.
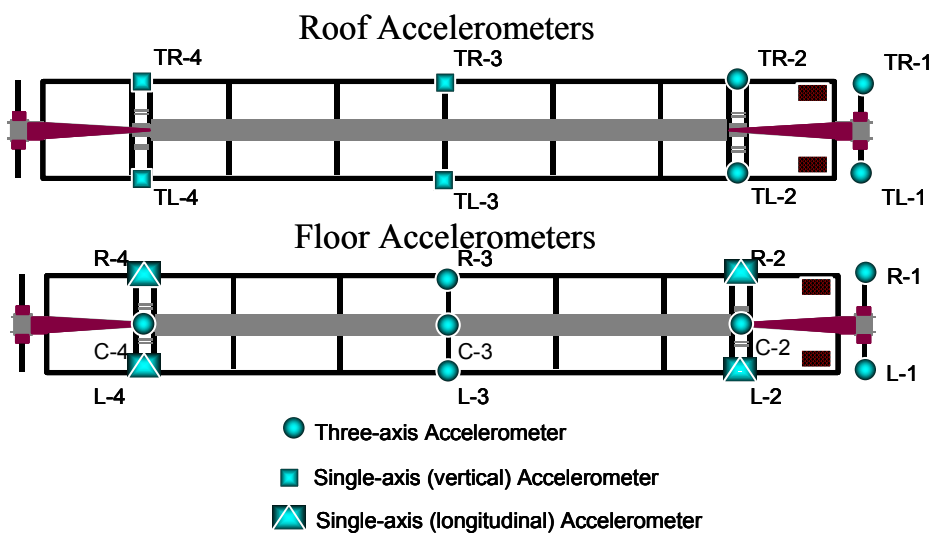

Figure A1. Accelerometer Locations on Cab Car

Nine accelerometers were placed on the steel coil as shown in Figure A2. All accelerometers had a range of 400 Gs. The following 9-array accelerometer configuration is used to provide a collection of data based on the local coordinate system of the coil [14]. This allows for the translational and rotational motions to be precisely measured. 


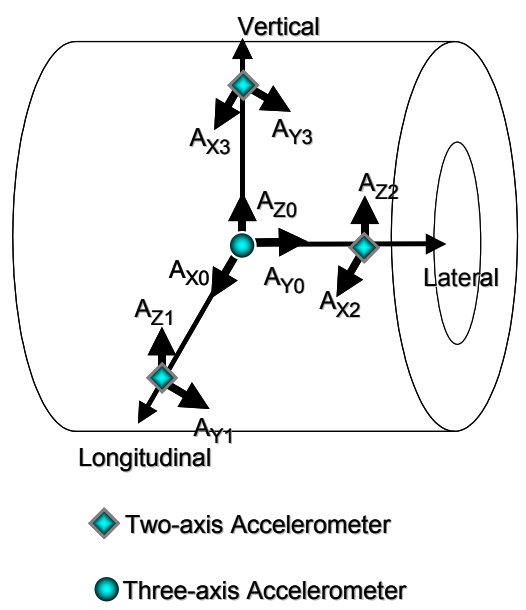

Figure A2. Accelerometer Locations on Heavy Object.

Nine string potentiometers were used in each test. Four string potentiometers were located on the passenger car between the body bolster and truck bolster to measure the relative vertical displacement of the suspension. Five string potentiometers were located on the corner post to measure its longitudinal deflection. Figures A3 and A4 show the locations and lengths of these displacement transducers relative to the corner post and the cab wall.

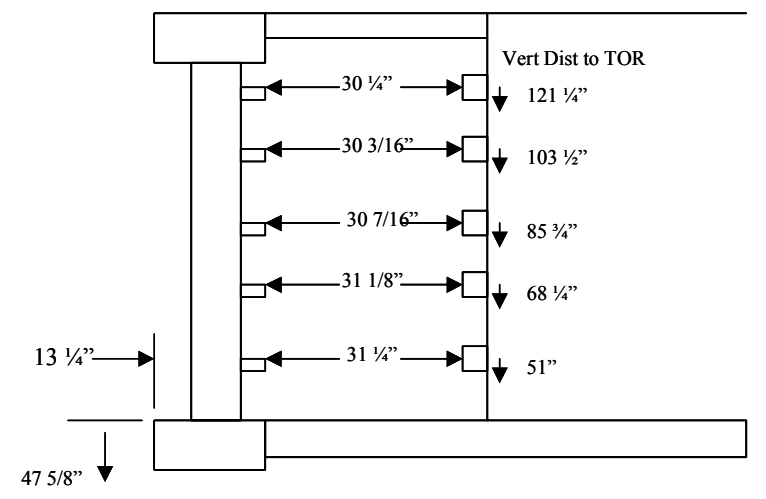

Figure A3. String Potentiometer Locations of 1990's Design

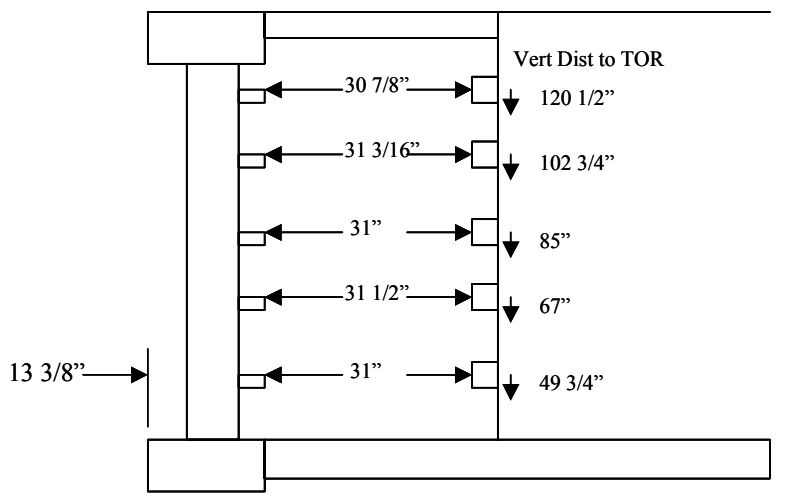

Figure A4. String Potentiometer Locations of SOA Design
Strain gauges were used to compare the structural response measured against the predicted. Details of the strain gauges are not mentioned because information regarding structural response is not reported in this paper.

Eight high speed cameras and four video cameras were used to record the impact from different the following angles: side-of-impact view of entire train, two side views focused on impact zone, head-on view, opposite side-of-impact angled view of front end, overhead view (camera located on a boom), and two on-board cameras (did not survive collisions). Placement of these cameras is shown in Figure A5. The exterior high speed cameras filmed at 300 frames per second and the interior cameras filmed at 500 frames per second. Upon impact contact switches, located on the coil and corner post, triggered flashes of light.

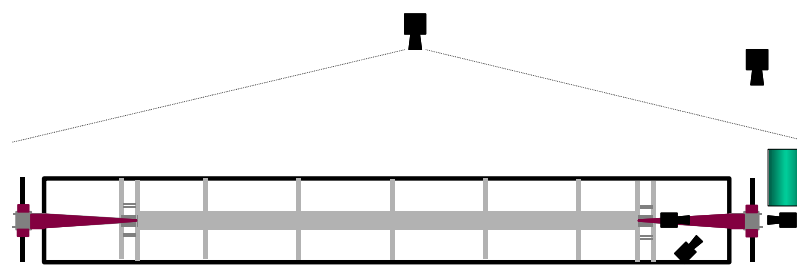

Figure A5. Schematic Layout of High Speed Camera Locations

Reflective 4-inch diameter targets, placed on the end structure facilitate photometric analysis of the film. The longitudinal and vertical coordinates of each target are identified with frame-by-frame grid analysis and the speeds and location of the specific elements are then calculated.

\section{APPENDIX B - PROCESSING OF TEST DATA}

All post-processing of test data follows the recommendations of SAEJ211-1, Instrumentation for Impact Tests [12]. The objective of post-processing the data is to correct time relative to initial collision impact, scale and filter data, and perform mathematical operations required to produce the results needed to compare test measurements to model predictions.

The raw data collected from the accelerometers is processed in multiple ways to provide the most useful comparisons. The sum of the mass times the acceleration-time histories of the colliding bodies yields the active collision force. This gives a reasonable estimate of the contact force predicted by the collision dynamics models.

The accelerometer data is also used directly to analyze the gross motions of the colliding bodies. The acceleration-time histories are integrated to acquire the velocity and displacement records. The impacting force-time history can then be plotted against the displacement, showing the force required to crush the end structure.

The raw accelerometer data recorded a noisy signal of the car body's motion. To make reasonable comparisons of acceleration-time histories, the data is filtered to extricate some of the high frequency content caused by the suspension, structural connections and accelerometer attachments. The filtered data shows the motion of the train as a rigid body. This data is compared to the motions produced by the collision dynamics models. The filtering process implemented is shown in Figure B1. 


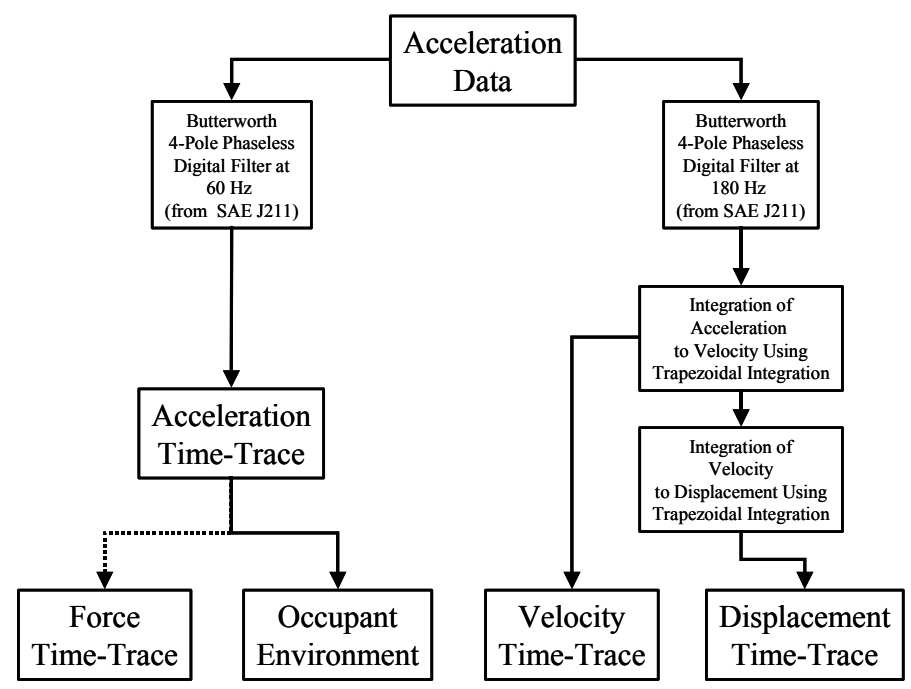

Figure B1. Post-Processing Flowchart

The filtering process was guided by the recommendations of SAE J211-1 [12], as well as the post-processing practices exercised in previous full-scale rail vehicle experiments. SAE J211-1 recommends frequency response classes for recording various components of fullscale data. A CFC 60 Butterworth 4-pole phaseless digital filter was used on the coil accelerometer data and CFC 15 filter was used on the carbody accelerometer data.

A representative accelerometer was determined to be located at the front side of impact on the draft sill. This location provided the most useful data because it was at the front of the train near the impact, but behind the end structure and area of crush. Accelerometers located towards the rear of the train not only have a time delay in their signal but provided noisier data because of the greater influence of the rear end of the carbody, which did not have an end structure.

Post-processing of strain gauges and string potentiometers includes filtering and plotting for comparisons and checks of valid results. Post-test analysis of the high-speed film is valuable to document vehicle displacements for comparison with integrated accelerometer data and with model results. 